\title{
JATROPHA CHAMELENSIS (EUPHORBIACEAE), NUEVA ESPECIE DE LA COSTA DE JALISCO, MEXICO
}

\section{ALFREDO PEREZ-JIMENEZ ${ }^{1}$}

\section{RESUMEN}

Se describe e ilustra una nueva especie de Euphorbiaceae: Jatropha chamelensis proveniente del Estado de Jalisco, México. Pertenece a la Sección Mozinna (Ort.) Pax, Subsección Mozinna (Ort.) Muell. Arg. y se distingue fácilmente de las especies mexicanas de esta Subsección por sus hojas grandes, anchas, no peltadas y glaucas en el envés. Se incluye descripción anatómica de la madera.

\section{SUMMARY}

A new species of Euphorbiaceae, Jatropha chamelensis, from Jalisco, Mexico is described and illustrated. It belongs to Section Mozinna (Ort.) Pax, Subsection for its large, broad, non peltate leaves, glaucous underneath. An anatomical description of the wood is included.

Durante los trabajos que se realizan en la Estación de Investigación, Experimentación y Difusión en Chamela, Jal., se colectó un árbol del género Jatropía; después de una cuidadosa revisión se llegó a la conclusión de que es una especie nueva para la ciencia. Además de ejemplares de herbario se colectó muestra de madera, la cual fue estudiada en el Laboratorio de Anatomía de Maderas del Instituto de Biología por la $M$. en $C$. Josefine Barajas $M$.

A continuación se hace una descripción de la especie en la que se incluye la anatomía de la madera.

Jatropha chamelensis Jérez-Jiménez, sp. nov.

Arbor dioica usque ad $12 \mathrm{~m}$ alta $20 \mathrm{~cm}$ diametro. Cortex flavus papyraceus. Folia orbiculata versus late deltoidea $11(-21) \mathrm{cm}$ longa, $12(-24) \mathrm{cm}$ lata, apice obtuso versus apiculato, base cordata, supra subviridia, infra glauca glaberrima, palmatinervia. Petioli $4-16 \mathrm{~cm}$ longi. Flores masculini ad cymas $13.5 \mathrm{~cm}$ longas, feminei axillares 1-3. Calix ô $3 \mathrm{~mm}$ longus, $+10 \mathrm{~mm}$. Corolla ( $\hat{o}$ et $q$ ) tubularis,

1 Instituto de Biología, UNAM. Apdo. Postal 70-233. México 20, D.F. México. 


\section{BOLETIN DE LA SOCIEDAD BOTANICA DE MEXICO No. 42, 1982}

lilacina vel atrorosea, $13 \mathrm{~mm}$ florum masculinorum, $15 \mathrm{~mm}$ femineorum. Stamina 10, pentadynama. Styli 3, stigmata bifida. Capsula globosa $4 \mathrm{~cm}$ diametro. Semina 3, ellipsoidea.

Arbol hasta de $12 \mathrm{~m}$ de alto y con diámetro a la altura del pecho hasta de $20 \mathrm{~cm}$, tronco recto, ramas ascendentes que a veces se vuelven horizontales. La copa es redondeada, abierta.

La corteza externa es lisa, amarillo pálida, papirácea, desprendible en tiras anchas, transversales, con lenticelas moreno amarillentas. La corteza interna es moreno rosada, blanda. Madera amarilla, blanda, con porosidad difusa y rayos delgados. Con látex rojo sangre en el tronco, en las ramas el látex es marillo pálido, muy viscoso.

Hojas dispuestas en espiral, simples; láminas papiráceas, generalmente más anchas que largas, de $11 \times 12$ a $21 \times 24 \mathrm{~cm}$, orbiculares a ampliamente deitoideas, con con el margen entero o repando, ligeramente revoluto, en ocasiones las hojas jóvenes tienen el margen ciliado-glanduloso, ápice obtuso a apiculado, base cordada, verde claras en la haz y glaucas en el envés, glabras en ambas superficies, con 5 nervios principales originados en la base, prominentes en el envés, los 3 centrales más gruesos; pecíolos de $4-16 \mathrm{~cm}$ de largo, en ocasiones diminutamente pubescentes. A los lados de la base del pecíolo se presenta una estípula caediza, ciliado glandulosa de $5-8 \mathrm{~mm}$ de largo. Los árboles de esta especie son caducifolios.

Especie dioica. Inflorescencias masculinas cimosas, en las axilas de las hojas nuevas o en la parte basal de las ramas jóvenes, con pubescencia comúnmente blanca, a veces ferruginosa: con una bráctea en cada bifurcación, ampliamente triangular, de $1 \mathrm{~mm}$ de largo, con pubescencia ferruginosa y ciliada; con una flor terminal en la bifurcación. Flores masculinas actinomorfas, de $15 \mathrm{~mm}$ de largo; pedicelos de $6-10 \mathrm{~mm}$ de largo; cáliz verdoso de $3 \mathrm{~mm}$ de largo, con 5 lóbulos ampliamente triangulares, valvados, la superficie externa seríceo vilosa, los pelos amarillo claro; corola lila o rosado intenso, tubular, de $13 \mathrm{~mm}$ de largo, expandiéndose en un limbo de 5 lóbulos de $2 \mathrm{~mm}$ de largo, triangulares, contortos, diminutamente pubescentes en ambas superficies, sobre todo en la externa; estambres 10, pentadínamos, los 5 más largos de $6 \mathrm{~mm}$, los más cortos de $3 \mathrm{~mm}$, ambos tipos de estambres con las anteras basifijas, sagitadas, con dehiscencia longitudinal, pero en los más cortos las anteras son péndulas, los filamentos están unidos en su base sobre un disco estaminal que lleva alrededor 5 glándulas esféricas de aproximadamente $1 \mathrm{~mm}$ de diámetro.

Flores femeninas 1-3 en las axilas de las hojas jóvenes, actinomorfas, sobre pedúnculos de 6-10 $\mathrm{mm}$ de alrgo, con pubescencia amarilla; sépalos 5 , de $10 \mathrm{~mm}$ de largo, subulados a espatulados, verdosos, con pubescencia seríceo vilosa en ambas superficies, la externa glauca, la interna ferruginosa. Corola gamopétala, lila a rosado intenso, globosa, de $15 \mathrm{~mm}$ de largo y $10 \mathrm{~mm}$ de diámetro en la base; con 5 lóbulos imbricados, de 3-5 $\mathrm{mm}$ de largo, reflejos en el ápice, la abertura de la corola 2-4 mm de diámetro, pubescente en el tercio distal de la superficie exterior y en la superficie interior de la parte refleja. Ovario súpero, verde, trilobular, con un óvulo en cada cavidad, el ovario está sobre un disco basal amarillo; estilos 3, unidos en la base, verde amarillentos; estigmas 3 , bífidos.

Cápsula de $4 \mathrm{~cm}$ de diámetro, globosa, 3 lobada, 6 valvada, amarillo verdosa, con el cáliz persistente; contiene 3 semillas amarillas, de $2 \mathrm{~cm}$ de largo, elipsoidales, con una cara ligeramente aplanada.

Descripción de la madera:

Descripción macroscópica. Madera homogénea sin diferencia notable entre duramen y albura, de color blanco crema, a veces ligeramente amarillenta o pardusca, sin 


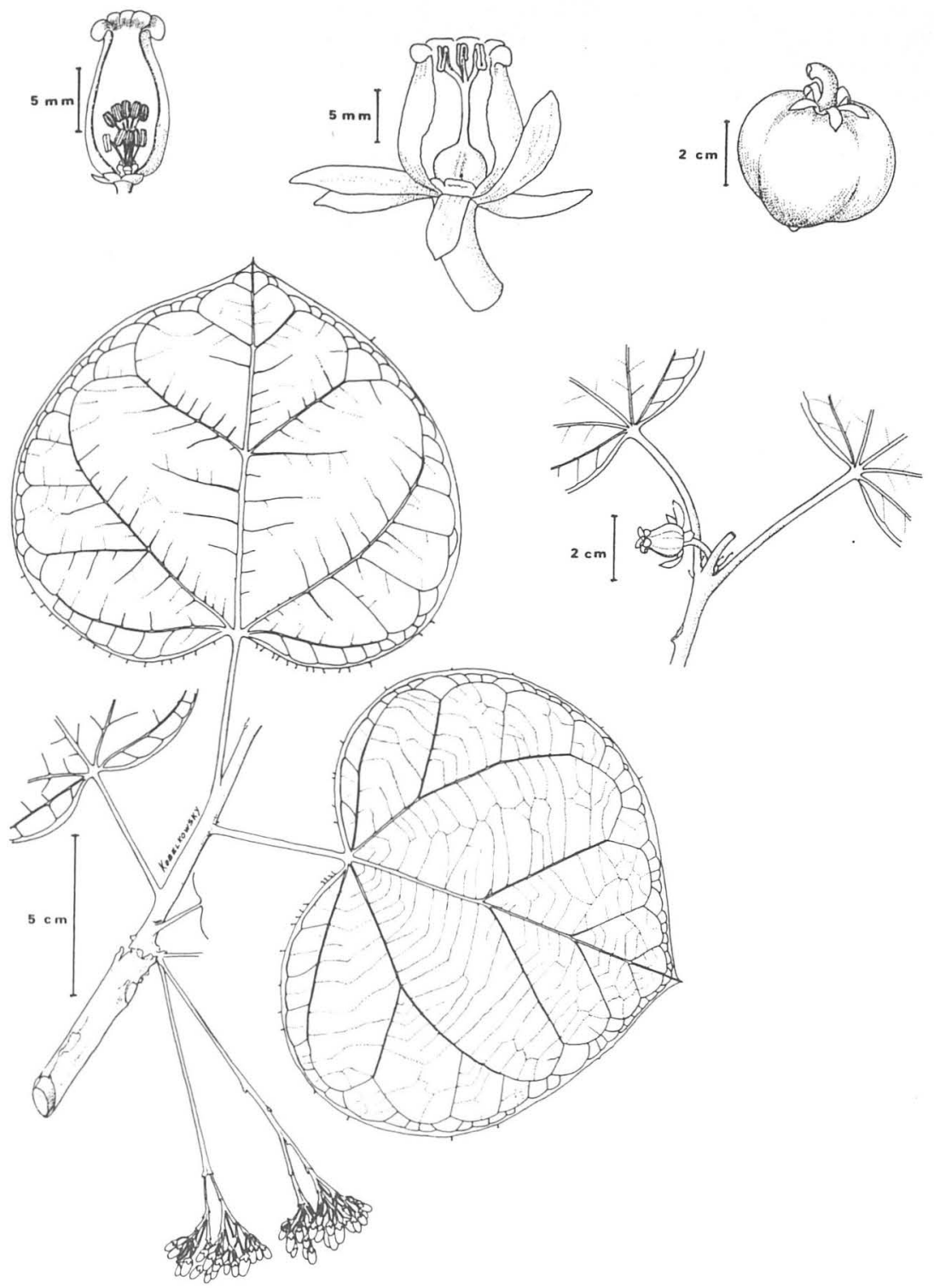

Figura 1. De izquierda a derecha: corte de una flor masculina, corte de una flor femenina, rama con inflorescencia masculina y detalle de rama con flor femenina. 
olor ni sabor, muy lustrosa y de textura áspera, grano recto y exageradamente blanda y ligera. En la cara transversal se aprecian a simple vista los anillos de crecimiento delimitados por una banda de tejido de color más obscuro que es al área más frágil de la madera y gracias a la cual ésta se separa fácilmente en capas. También se aprecian con facilidad los poros medianamente numerosos.

Descripción microscópica. Madera con porosidad difusa, con poros ovalados moderadamente numerosos, solitarios y en grupos o cadenas radiales de 2 a 9 siendo los más abundantes los grupos de 3 a 6 . Los elementos de vaso son moderadamente largos (680 mm) con platina de perforación simple y puntuaciones alternas, grandes, de abertura lenticular. El parénquima axial es muy abundante, apotraqueal difuso en agregados y paratraqueal escaso, además de marginal en bandas de hasta 6 células de grosor. Los ravos son heterocelulares uni y biseriados, muy bajos $(900 \mu \mathrm{m})$, formados por células cuadradas y erectas, a veces homocelulares. Las fibras son de longitud mediana (1000 $\mu \mathrm{m})$ y con paredes muy delgadas $(2 \mu \mathrm{m})$ y lúmenes grandes.
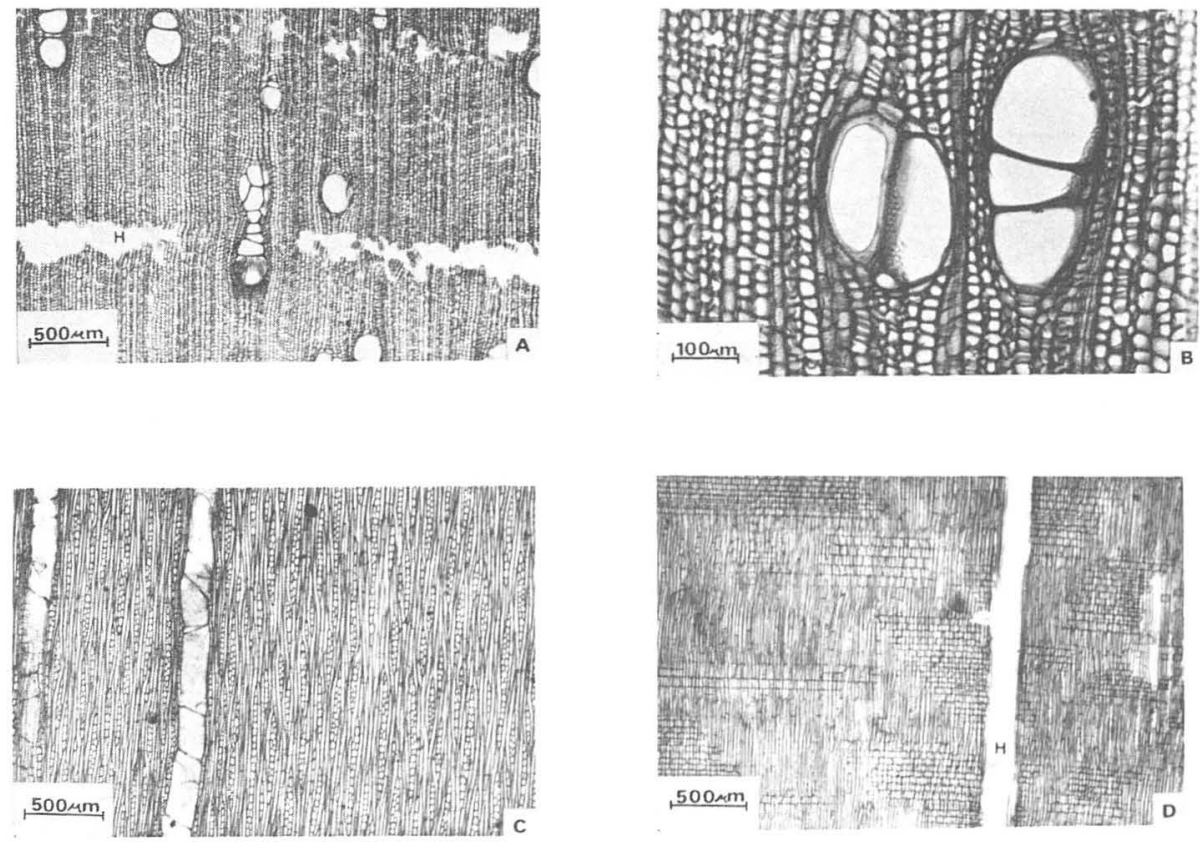

Figura 2. Madera de Jatropha chamelensis Pérez-Jiménez. A y B, secciones transversales; C, sección tangencial; $\mathrm{D}$, sección radial; $\mathrm{H}$ indica las áreas en donde el tejido se separa naturalmente.

Esta especie está dentro de la Sección Mozinna (Ortega) Pax, Subsección Mozinna (Ortega) Muell. Arg. según las considera McVaugh (1945), por las siguientes características: planta dioica; cáliz de las flores + herbáceo, diferente y más grande que el 
de las flores $\mathbf{8}$; corola tubular lila a rosado intenso, el tubo más largo que los lóbulos; ramas de la inflorescencia $\hat{\delta}$ opuestas o subopuestas, con una flor terminar en la bifurcación; estambres 10; fruto capsular y semilla globular. Jatropha chamelensis se distingue fácilmente de las otras 19 especies mexicanas de esta Subsección por tener las hojas grandes y anchas, Jatropha platyphylla Muell. Arg. es la que más se le parece, pues también tiene las hojas grandes y anchas, pero peltadas y lobadas.

El nombre de esta especie se refiere al poblado Chamela, el más cercano a la zona de hallazgo. Este poblado se localiza en el Municipio de La Huerta en el Estado de Jalisco, México.

Se le conoce en la región de Chamela, en la costa de Jalisco, México. Forma parte de selvas bajas caducifolias asociada con Caesalpinia eriostachys. Cordia elaeagnoides, Lysiloma divaricata, Caesalpinia coriaria, Ampbipterygium adstringens, etc., sobre suelos someros derivados de riolitas. Los árboles de esta especie florecen de mediados de junio a fines de julio y pierden las hojas de noviembre a mayo. Su nombre común en la región es "papelillo".

TIPO: México, Jalisco: Estación de Biología de Chamela, Municipio de La Huerta, altitud $110 \mathrm{msnm}$ L. Alfredo Perez-Jimenez 1743. Holotipo (MEXU), Isotipo (ENCB). Otros isotipos serán distribuidos próximamente.

Material adicional examinado: México, Jalisco, Estación de Biología de Chamela, Municipio de La Huerta: julio 18 de 1976 (frutos), A. Delgado S. 329 y R. Hernandez 2580 (MEXU); noviembre 3 de 1973 (estéril), L. A. Perez-Jimenez 797 (MEXU); julio 17 de 1974 (frutos inmaduros), L. A. Perez-Jimenez 872 (MEXU); julio 17 de 1974 (flores ô y madera), L. A. Perez-Jimenez 874 (MEXU); agosto 13 de 1974 (frutos), L. A. Perez-Jimenez 959 (MEXU); julio 1 de 1978 (flores $\hat{b}$ ), L. A. Perez-Jimenez 1744 (MEXU, ENCB); julio 1 de 1978 (flores $\hat{b}$ ), L. A. Perez-Jimenez 1745 (MEXU, ENCB); julio 1 de 1978 (plántulas), L. A. Perez-Jimenez 1750 (MEXU); julio 1 de 1978 (estéril), L. A. Perez-Jimenez 1757 (MEXU); julio 29 de 1978 (frutos), L. A. Perez-Jimenez 1821 (MEXU, ENCB).

\section{AGRADECIMIENTOS}

A los Dres. Jerzy Rzedowski y Mario Sousa por la revisión del manuscrito y por sus valiosas sugerencias. Al Dr. Fernando Chiang quien hizo la traducción al latín de la diagnosis y al $\mathrm{M}$. en C. Abraham Kobelkowsky quien amable y diligentemente realizó los dibujos. Deseo agradecer muy especialmente a la $\mathbf{M}$. en C. Josefina Barajas el haberme proporcionado la descripción de la madera y las fotomicrografías que ilustran este artículo.

\section{LITERATURA CITADA}

McVAUGH, R. 1945. The genus Jatropha in America: principal intrageneric groups. Bull. Torrey Bot. Club 72 (3): 271-294. 